\title{
STABILITY APPRAISAL OF THE MEDVEDOVA KONTA POTHOLE
}

\author{
Jože KORTNIK
}

\begin{abstract}
Until 1956 the underground details of areas around Pokljuka were practically unknown due to the area's non-karstic outward appearance. However, the presence of karst phenomena on this Alpine plain is undoubtedly indicated, primarily by the absence of a surface drainage network. A mathematical model was made of the Medvedova konta pothole, in which two different sets of material properties were used, corresponding to the Triassic limestone that forms the bedrock under the greater part of Pokljuka. The model simulates the gradual thinning of the ceiling of the underground hall, from the surface downwards, until its collapse.

The paper presents a stability appraisal of the Medvedova konta pothole in Pokljuka.
\end{abstract}

KEY WORDS: Medvedova konta pothole, stability appraisal.

\section{Introduction - the Medvedova konta pothole}

The history of research at the Medvedova konta pothole dates back to 1956, when a group of speleologists (J. Kunaver) first heard about this $200 \mathrm{~m}$-deep pothole from a Pokljuka forester. Until that year, underground features were practically unknown in the area around Pokljuka, primarily because this Alpine plain does not have a karstic appearance, as do, for example, the Jelovica, Mežakla or other plains surrounding the Slovene Alpine massifs. However, the presence of karst phenomena at Pokljuka is undoubtedly indicated, primarily by the absence of a surface drainage network in the central part, and by the presence of large sinkholes. The in the greater part of the Pokljuka area is Triassic limestone, on which a kind of covered or latent mountain karst has formed at the surface due to the presence of younger sediments and rock. In this case, surface karst phenomena are less numerous and less pronounced, and this is especially true of the youngest surface forms.

The entrance to the Medvedova konta pothole lies at an elevation of about $1390 \mathrm{~m}$, in the northwestern, upper part of Medvedova konta, between the peaks of Liparski vrh (1983m), Brdo (1844m), Okroglež (2009m) and Debela peč (2015m), where the Pokljuka plain begins to rise into the Pokljuka ridge.

The entrance void was formed along a major fault line, which runs NNW-SSE and is clearly visible at the surface. First, a deep and very steep sinkhole was formed along this fault line. On one side of the sinkhole is a vertical wall that continues into a pothole at its base, and then widens out into a hall at a depth of $45 \mathrm{~m}$. The dimen- 
sions of the pothole, which has a rectangular profile along its entire length, are $6 \times 3 \mathrm{~m}$ at the top, expanding to $9 \times 5 \mathrm{~m}$ towards the transition into the hall. The pothole merges with the hall at its extreme southern end. The highest part of the hall ceiling is not at the point of the shaft's entry, but is above the eastern part of the hall, and is estimated to be about $57 \mathrm{~m}$ above the floor. The circumference of the hall is $433 \mathrm{~m}$, and the ground plan of the hall is an irregular circle, with a maximum width of $152 \mathrm{~m}$ and a minimum width of $132 \mathrm{~m}$ (Fig. 1). The hall floor slopes towards the middle, from the southern and western parts to the north-western part. Approximately one third of the floor between the northern and the western parts of the hall is relatively level. In two places, the hall floor drops into potholes, both of which are of known depth. The first was formed in a similar manner to the entry pothole, near the fault line, right beside the hall wall. It is $20 \mathrm{~m}$ deep, and at an elevation of $142 \mathrm{~m}$, its foot is the lowest point of the Medvedova konta pothole (Kunaver, J., 1960).

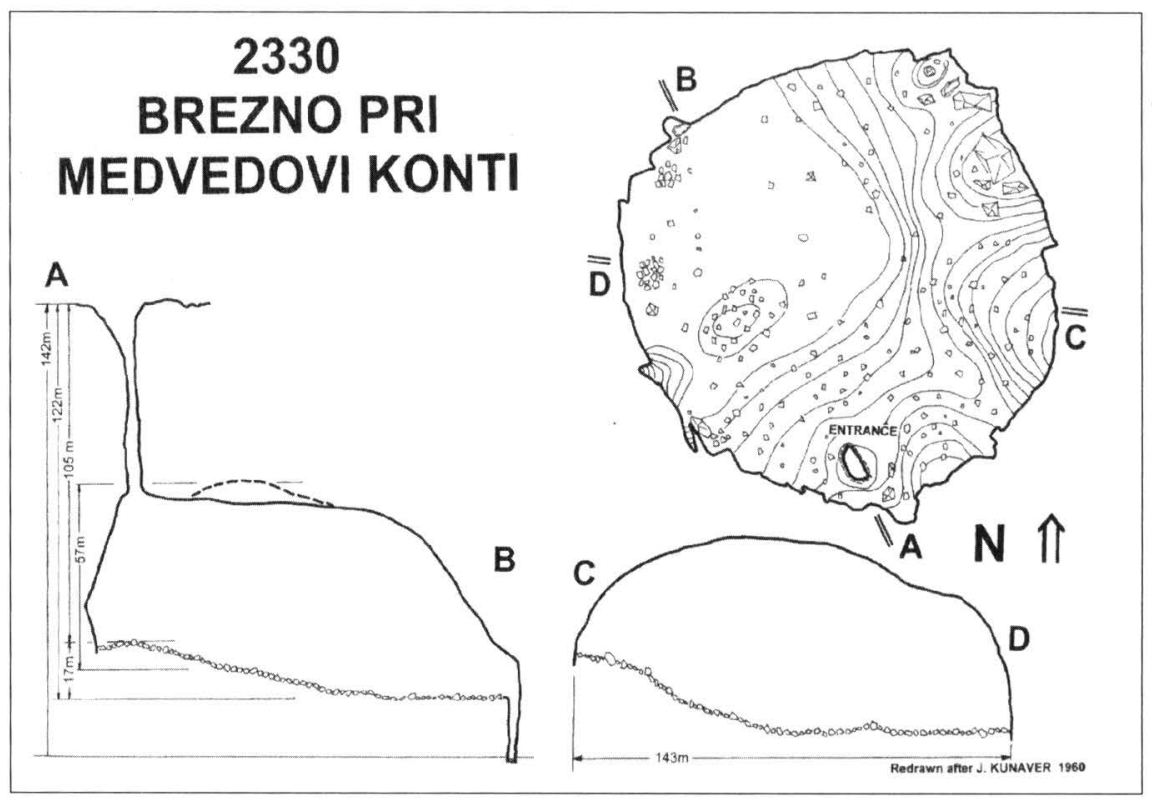

Fig. 1 - The Medvedova konta pothole.

\section{Stability appraisal}

A stability appraisal of the Medvedova konta pothole was made using the FLAC (Fast Lagrangian Analysis of Continua) numerical software package. The program is a two-dimensional explicit finite difference program for engineering mechanics computation. It offers a wide range of capabilities to solve complex problems in mechanics. Materials are represented by elements within a grid that is adjusted by the user to fit the shape of the object to be modelled. Each element behaves according to a prescribed linear or non-linear stress/strain law in response to applied forces or boundary restraints. The material can yield and flow, and the grid can deform and move with the material that is represented. The program is based on a Lagrangian 
calculation scheme that is well suited for modelling large distortions and material collapse (Coetzee et al., 1993).

\section{Primary stress state}

The thickness of the ceiling of the hall in Medvedova konta is approx. 59m, which means that the roof of the main hall is located relatively close to the surface. In such cases, the ratio of horizontal to vertical stress varies considerably, but generally the horizontal stress $\sigma_{H}$ exceeds the vertical stress $\sigma_{V}$. Diagrams of coefficient $k$ versus depth were made on the basis of numerous measurements in different types of rock (Brady and Brown, 1985).

$$
k=\frac{\sigma_{H}}{\sigma_{V}}
$$

For a depth of $100 \mathrm{~m}$, the coefficient k ranges between 1.3 and 3.5 . In the model, the value of $\mathrm{k}$ was assumed to be 1 .

\section{The model of the Medvedova konta pothole - profile C-D}

One model was made, in which two different sets of material properties were used, each corresponding to possible properties of the Triassic limestone. The sets of material properties shown in the table below confirm the stability of the model before the beginning of the thinning of the ceiling.

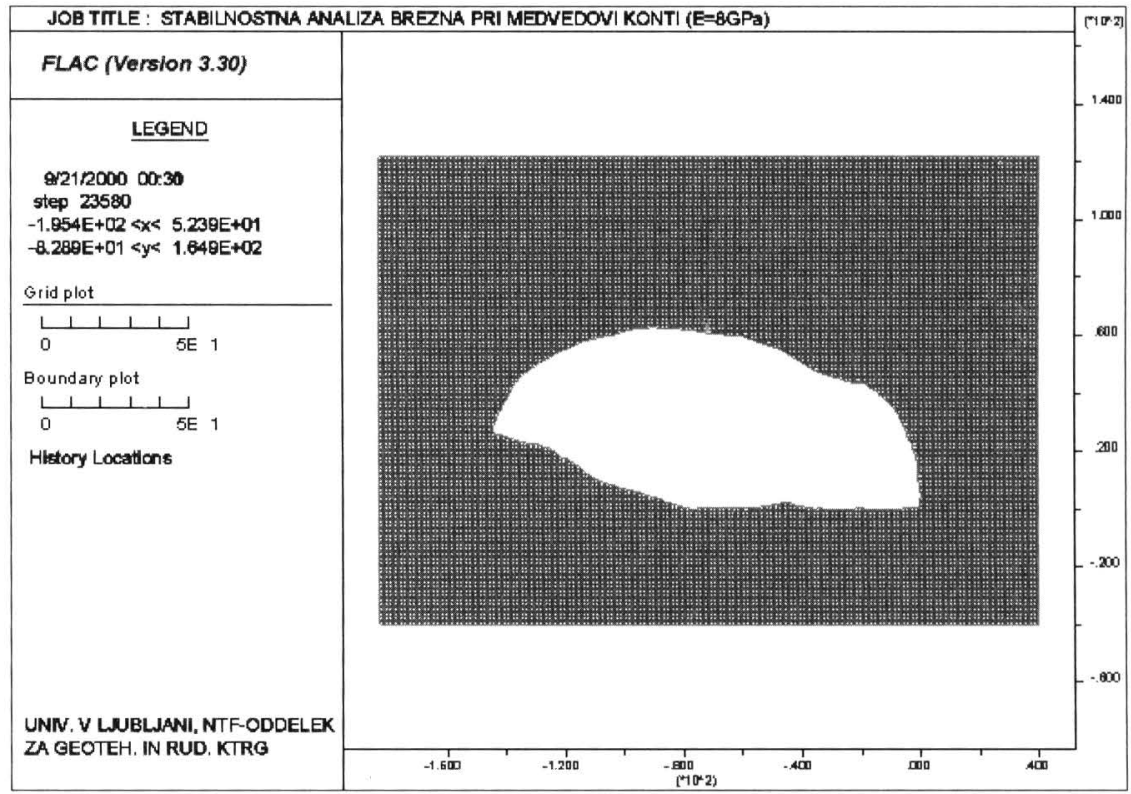

Fig. 2 - Model of the Medvedova konta pothole - profile CD (Figure 1.). 
The model simulates the gradual thinning of the hall ceiling from the surface downwards, until its collapse. The grid size is $223 \times 162$ elements. The MohrCoulomb plasticity model was used.

Table 1. Sets of rock properties used in the model

\begin{tabular}{|c|c|l|c|c|}
\hline Designation & Unit & & Set 1 & Set 2 \\
\hline $\mathbf{E}$ & $(\mathrm{GPa})$ & Modulus of elasticity & 8 & 25 \\
\hline$v$ & & Poisson's ratio & 0.25 & 0.25 \\
\hline$T$ & $(\mathrm{MPa})$ & Tensile strength & 1.85 & 4 \\
\hline$\gamma$ & $\left(\mathrm{kg} / \mathrm{m}^{3}\right)$ & Density & 2732 & 2732 \\
\hline$C$ & $(\mathrm{MPa})$ & Cohesion & 1.1 & 1.1 \\
\hline$\varphi$ & $\left(^{\circ}\right)$ & Friction angle & 35 & 35 \\
\hline
\end{tabular}

Three control points were chosen in the rock above the hall ceiling, where displacement development was monitored. The model was treated as stable if the displacement values at control points converged towards an end value. In the opposite case, the development of displacement values indicated the collapse of the hall ceiling.

\section{Results of modelling}

In the model, thinning of the hall ceiling was simulated by introducing gradual decreases of the cover thickness downwards from the surface side. This was performed in 10 steps, and the results are shown in Table 2.

Table 2. Maximum displacements during the thinning modelled in the hall ceiling.

\begin{tabular}{|c|c|c|c|l|}
\hline Step & $\begin{array}{c}\text { Cover height } \\
(\mathrm{m})\end{array}$ & $\begin{array}{c}\text { Max. displacement } \\
\text { Set 1 } \\
(\mathrm{mm})\end{array}$ & $\begin{array}{c}\text { Max. displacement } \\
\text { Set 2 } \\
(\mathrm{mm})\end{array}$ & Appendix \\
\hline 1. & 59 & 68.4 & 21.9 & \\
\hline 2. & 50 & 63.9 & 20.4 & \\
\hline 3. & 40 & 59.9 & 19.1 & \\
\hline 4. & 30 & 57.8 & 18.4 & \\
\hline 5. & 20 & 59.6 & 19.0 & Figure 5, 6. \\
\hline 6. & 15 & 63.7 & 20.3 & \\
\hline 7. & 10 & 83.3 & 26.7 & \\
\hline 8. & 8 & 107.7 & 34.6 & \\
\hline 9. & 6 & 154.0 & 49.4 & \\
\hline 10 & $<6$ & collapse & collapse & \\
\hline
\end{tabular}

For both modelled sets of rock properties, the hall ceiling collapses when its thickness falls below $4 \mathrm{~m}$. Plastic areas appear in the rock near the ceiling and hall sides throughout the modelling. They are especially common in the area of the left and right hall sides, and, with the thinning of the ceiling, they migrate towards the hall ceiling and the surface. In places where the ceiling is thinner than $20 \mathrm{~m}$, there are gradual indications of the possibility of hall ceiling collapse. The maximum dis- 
placements appear at the edges of the hall (Fig.3).

Throughout the modelling, the maximum displacements appear in the hall ceiling and decrease towards both sides of the hall. The development of displacements at the control points of the model indicate a decrease in the maximum displacements with a decrease in ceiling thickness to $30 \mathrm{~m}$. With further modelling, displacements gradually increase with thinning of the hall ceiling, up until complete collapse (Fig.4).

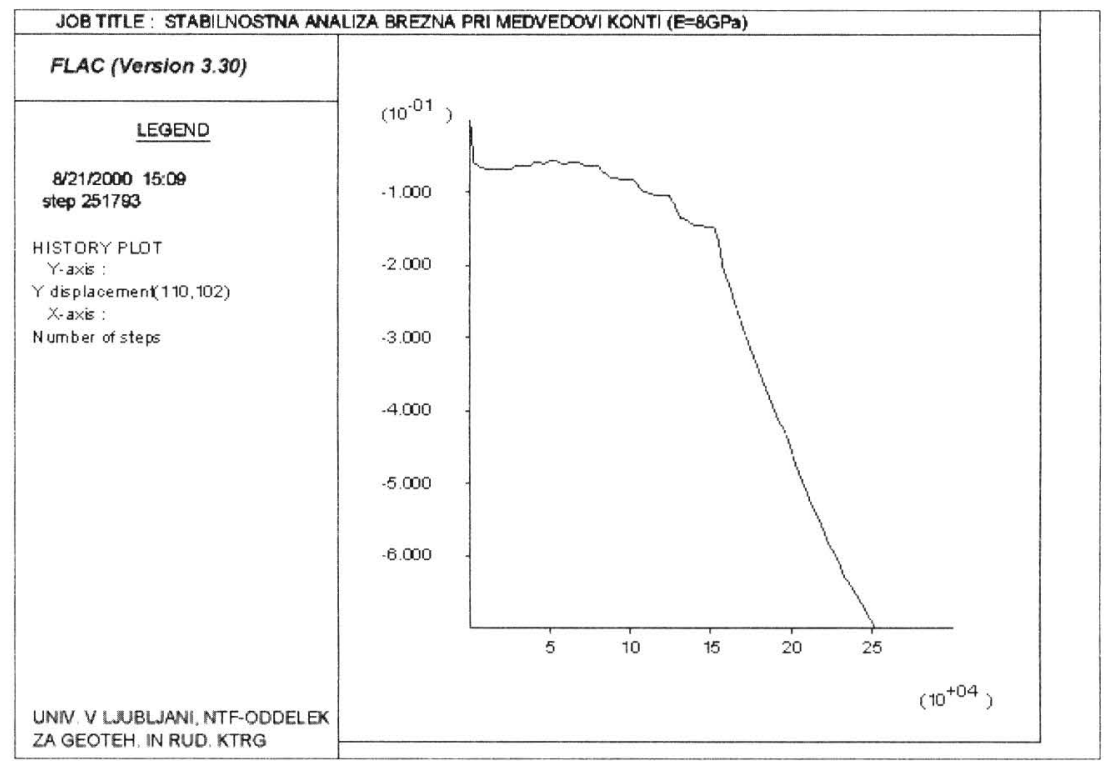

Fig. 3 - History of y-displacement at point $1(110,102)$.

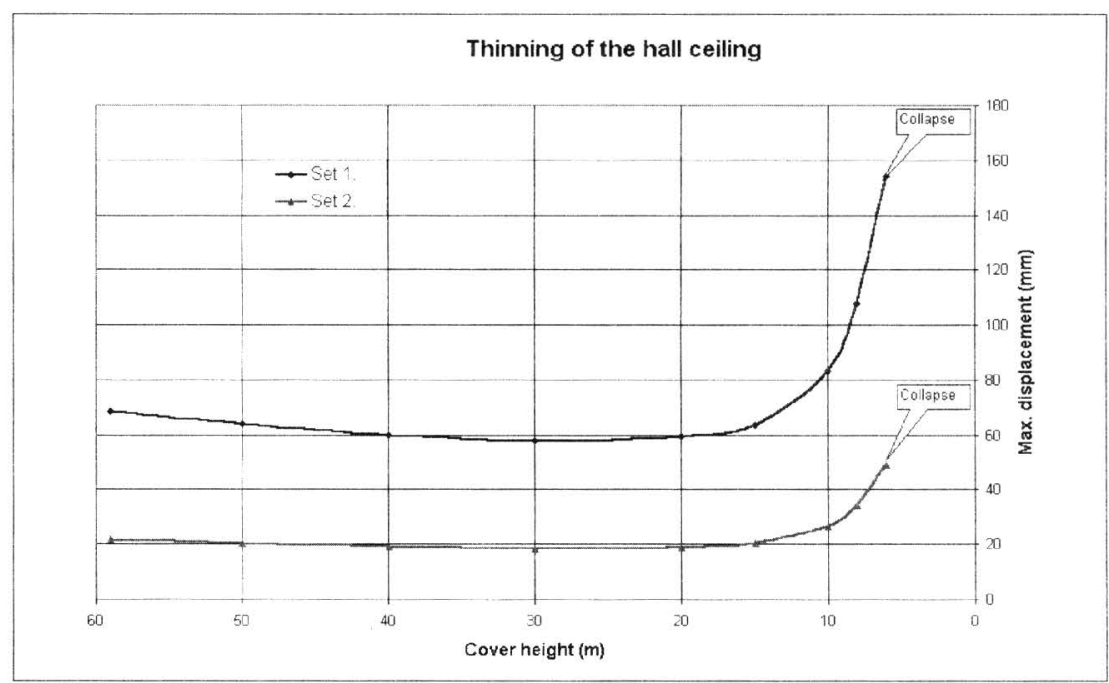

Fig. 4 - Thinning of the Medvedova konta hall ceiling. 
Solid rock, such as the Triassic limestone, is characterised by brittle breakage. Since such rock can withstand only low percentage plastic strain, any appearance of plastic areas in the model represents a potential danger of hall ceiling collapse (Figs 5 and 6).

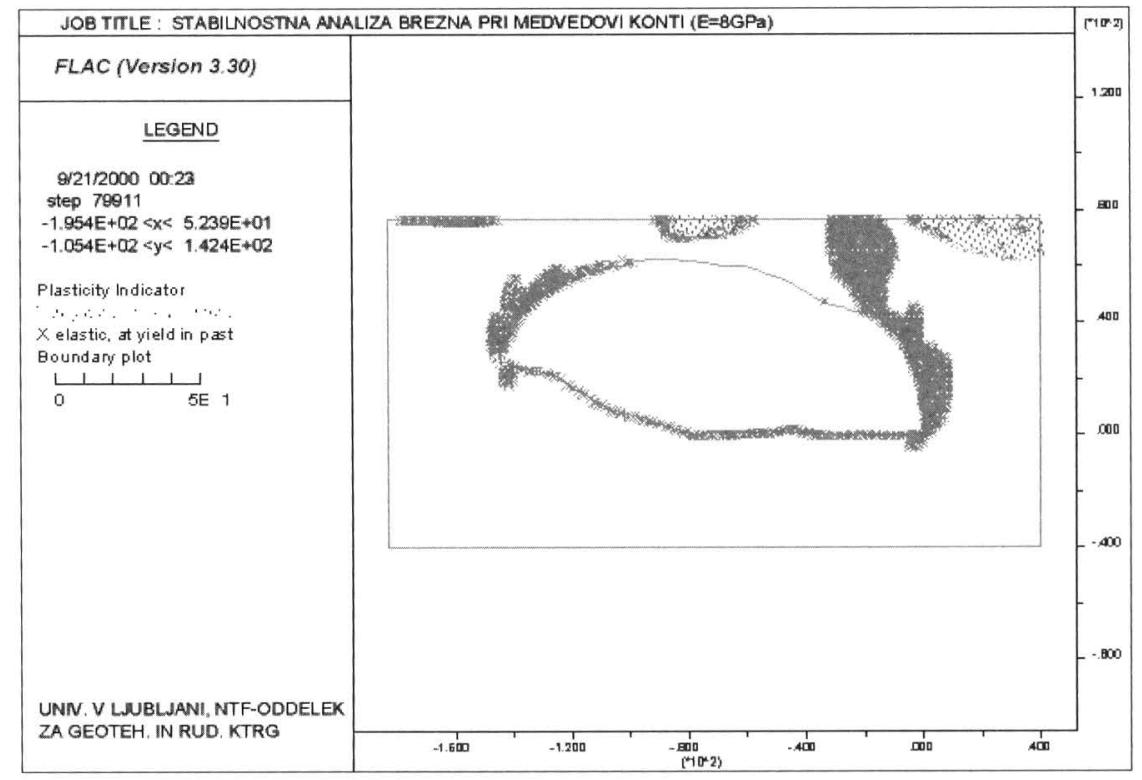

Fig. 5 - Plasticity indicators in the surroundings of the hall area (ceiling thinner than 20m).

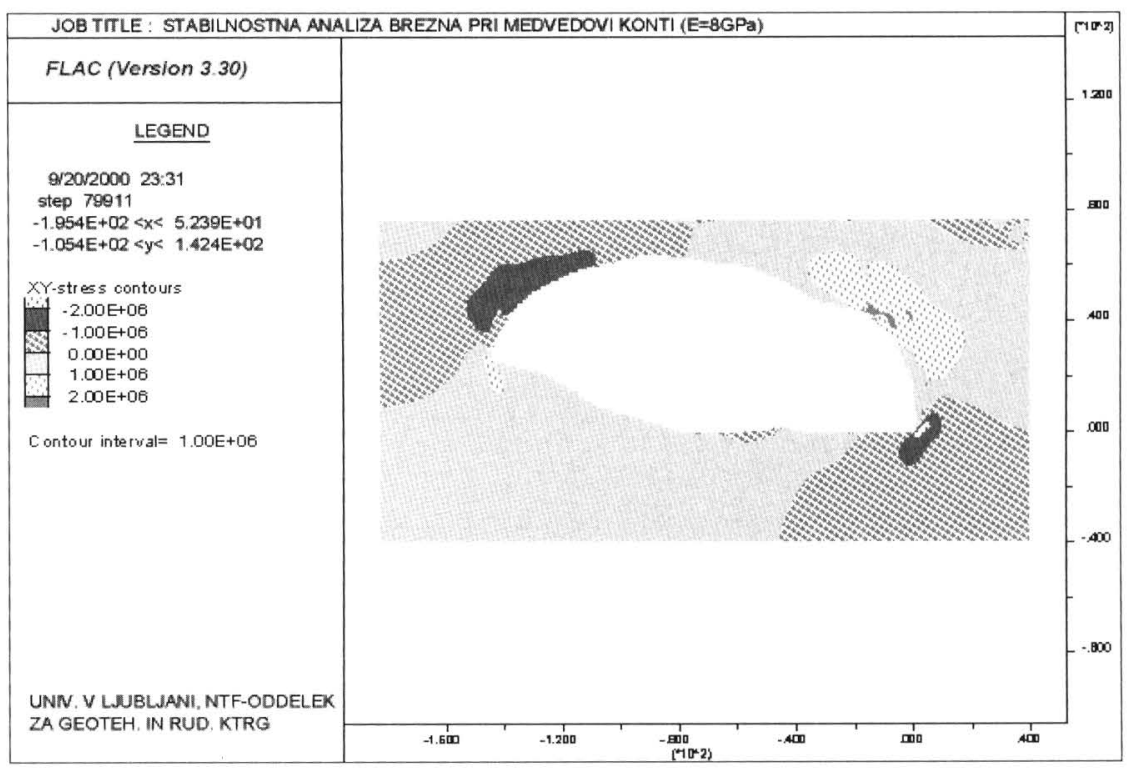

Fig. 6 - Shear stresses in the surroundings of the hall area (ceiling thinner than 20m). 


\section{Conclusions}

The model presented demonstrate that a hall ceiling collapse is an underground-rooted surface karst form. More precisely, it may be considered as a non-karstic projection of a karst void onto the karst surface (Sustersic, 2000).

The stability appraisal presented in this paper was used for study and research purposes at the Medvedova konta pothole. Modelling results of the type presented can contribute to an understanding of the mechanisms of sinkhole formation.

\section{REFERENCES}

BRADY B.H.G. and BROWN E.T. 1985. Rock Mechanics for Underground Mining. Allen \& Unvin: $149 \mathrm{p}$.

COETZEE M.J., HART R.D., VARONA P.M. and CUNDALL, P.A. 1993. FLAC Basics. Itasca Consulting Group Inc., Minneapolis: 1-3.

KORTNIK J. and ŠUSTTERŠIČ F. 2000. Modeling the stability of a very large cave room, case study: Brezno pri Medvedovi Konti. Acta carsologica 29 (2), Ljubljana: 149-160.

KUNAVER J. 1960. Brezno pri Medvedovi konti na Pokljuki (Summary). Nase jame 2 (1-2), Ljubljana: 30-39.

ŠUŠTERŠIČ F. 2000: Are Collapse Dolines Formed Only by Collapse? Acta carsologica 29 (2): 213-230. 